Results Valdecoxib produced no observable effects on Days 1 and 8 on platelet aggregation responses to AA, collagen, or ADP. Compared to placebo, valdecoxib produced no significant differences at any assessment. In contrast, naproxen significantly reduced all three platelet aggregation responses compared to placebo at most assessment times. The diclofenac group experienced significant reductions in AA-induced platelet aggregation compared to placebo at most assessment times, with fewer significant changes observed in response to collagen and ADP. Valdecoxib also had no effect on bleeding time compared to placebo $(\mathrm{p}>=0.136)$. Serum $\mathrm{TxB}_{2}$ was not significantly altered from baseline for either valdecoxib or placebo at any assessment time ( $\mathrm{p}>=0.267$ ), while significant differences from baseline were seen for naproxen at all assessment times when compared to placebo $(\mathrm{p}<=0.002)$.

\begin{tabular}{|c|c|c|c|c|}
\hline & Placebo & $\begin{array}{l}\text { Valdecoxib } \\
40 \mathrm{mg} \text { BID }\end{array}$ & $\begin{array}{l}\text { Naproxen } \\
500 \mathrm{mg} \text { BID }\end{array}$ & $\begin{array}{l}\text { Diclofenac } \\
75 \mathrm{mg} \text { BID }\end{array}$ \\
\hline Med. change $-30 \mathrm{~min}$ & 3.0 & 4.0 & $-80.0^{* * *}$ & -3.5 \\
\hline Med. change $2 \mathrm{~h}$ & 3.0 & 3.0 & $-81.0^{* * *}$ & $-8.5^{* *}$ \\
\hline Med. change $4 \mathrm{~h}$ & 0.0 & 3.0 & $-79.0^{* * *}$ & $-41.0^{*}$ \\
\hline Med change $8 \mathrm{~h}$ & 2.0 & 2.0 & $-80.0^{* * *}$ & $-11.0^{* *}$ \\
\hline
\end{tabular}

Platelet Aggregation Response to Arachidonate (\%), Median Change From Baseline After the Final Dose on Day $8\left({ }^{*} p<0.05\right.$ vs placebo, ${ }^{* *} p<0.01$ vs placebo, ${ }^{* * *} p<0.001$ vs placebo).

Conclusion The lack of effect on platelet aggregation and bleeding time would suggest that valdecoxib will have an improved clinical safety profile over conventional NSAIDs, particularly in patients for whom bleeding complications are a concern.

Sponsored by Pharmacia Corporation and Pfizer, Inc.

\section{SAT0059 GREATER EFFICACY FOR DICLOFENAC/MISOPROSTOL (ARTHROTEC) COMPARED TO ACETAMINOPHEN IN A RANDOMISED, DOUBLE-BLIND, MULTICENTER, CROSSOVER CLINICAL TRIAL IN PATIENTS WITH OSTEOARTHRITIS OF THE HIP OR KNEE IS MOST EVIDENT IN PATIENTS WITH THE MOST SEVERE OSTEOARTHRITIS}

T Sokka, T Pincus. Division of Rheumatology, Vanderbilt University, Nashville, USA

\subsection{6/annrheumdis-2001.434}

Background Acetaminophen (paracetamol) is recommended as initial therapy for osteoarthritis of the hip or knee according to guidelines of the American College of Rheumatology (ACR) prior to use of nonsteroidal anti-inflammatory drugs (NSAIDs), athough patient surveys indicate that most patients regard NSAIDs as having greater efficacy than acetaminophen.

Objectives To compare responses of patients with osteoarthritis of the hip or knee in a randomised, controlled clinical trial of diclofenac/misoprostol (Arthrotec, ARTH) compared to acetaminophen (ACET) according to severity at baseline of scores of the Western Ontario McMaster (WOMAC) osteoarthritis scale and visual analogue scale (VAS) for pain, the two primary outcomes in the clinical trial.

Methods 227 patients with radiographic stage 2-4 osteoarthritis of the hip or knee received either 6 weeks of ARTH $75 \mathrm{mg}$ twice a day or ACET 1,000 mg four times a day after a washout period, and then the other drug for 6 weeks, in a randomised, double-blind, multicenter, cross-over clinical trial. Changes in scores for the two primary outcomes while taking ACET or ARTH were analysed accoring to tertiles at baseline for each scale.

Results Overall, WOMAC pain scores were improved by 7.8 of 100 units $(\mathrm{p}<0.001)$, and pain VAS scores were improved by 14.6 of 100 units $(\mathrm{p}<0.001)$, while taking ARTH verus ACET. Differences between changes in WOMAC scores while taking ARTH versus ACET were 3.1 for patients in the lowest tertile at baseline $(\mathrm{p}=0.30)$, compared to 9.5 for the middle tertile $(\mathrm{p}<$ 0.001 ), and 12.2 for those in the highest baseline tertile ( $\mathrm{p}<$ 0.001). Differences between changes in pain VAS scores while taking ARTH versus ACET were 4.9 for patients in the lowest tertile at baseline $(p=0.25)$, compared to 16.6 for the middle tertile $(p<0.001)$, and 21.0 for those in the highest baseline tertile $(\mathrm{p}<0.001)$.

Conclusion Patients with mild osteoarthritis of the hip or knee have similar responses to ARTH and ACET, possibly because patients in the lowest tertile have the least capacity for improvement. Patients with more severe osteoarhtritis appear much more likely to benefit from ARTH.

\section{SAT0060 OSTEOARTHRITIS (OA) OF THE HIP: TOLERANCE AND EFFICACY OF INTRA-ARTICULAR HYALURONIC ACID (HA)}

O Brocq, V Breuil, G Tran, C Grisot, P Flory, L Euller-Ziegler. Rheumatology Department, University Hospital Archet 1, Nice, France

\subsection{6/annrheumdis-2001.435}

\section{Background}

Objectives Intra-articular injection of $\mathrm{HA}$, a visco-supplement, can be an interesting option to treat OA; it has been mostly studied for OA of the knee. We studied the short-term tolerance and efficacy of an intra-articular injection of Hylane G-F 20 (Synvisc) in hip OA.

Methods We performed an open prospective study in patients with OA of the hip (radiological and/or CT scan criteria: Kellgren radiological score $40 \mathrm{~mm}$ and/or Lequesne score $>6$ ), without surgery schedule for one year and without any pathology which may contribute to the pain. For each patient, articular amplitudes, VAS and Lequesne score were recorded at day $0,30,60,90,120$. The injection of one vial of the drug was realised after radiological verification of the position of the needle by injecting $1 / 2 \mathrm{cc}$ of a iodic contrast fluid. After

Results 30 injections were performed in 22 patients $(13 \mathrm{~F}+9$ $\mathrm{M})$, mean aged 54.7 years (37-83). The Kellgren score was: stade 1(2); st 2(11); st 3(9). Two patients with iode allergy were pre-treated by hydroxyzine. The patients received analgesics (all); NSAID (11); MOA (15).

\begin{tabular}{|c|c|c|c|c|c|}
\hline & Day 0 & Day 30 & Day 60 & Day 90 & Day 120 \\
\hline $\begin{array}{l}\mathrm{N}^{\circ} \text { of patients } \\
\text { VAS }(\mathrm{mm})\end{array}$ & 22 & 22 & & & \\
\hline
\end{tabular}

Conclusion Hylane G-F20 injection in the hip joint appeared to be well tolerated. It may have a special interest in patients $<60$ years old suffering from hip OA, notably for delaying surgery. 